Article

\title{
Spiculisporic Acids B-D, Three New $\gamma$-Butenolide Derivatives from a Sea Urchin-Derived Fungus Aspergillus sp. HDf2
}

\author{
Rong Wang ${ }^{\dagger}$, Tian-Mi Liu ${ }^{\dagger}$, Ming-Hui Shen, Ming-Qiu Yang, Quan-Ying Feng, Xian-Ming Tang \\ and Xiang-Min $\mathrm{Li}$ *
}

Hainan Provincial Fisheries Research Institute, Haikou 570203, Hainan, China

$\dagger$ These authors contributed equally to this work.

* Author to whom correspondence should be addressed; E-Mail: hn.lxm@163.com;

Tel.: +86-898-6651-7579; Fax: +86-898-6652-7571.

Received: 18 October 2012; in revised form: 30 October 2012 / Accepted: 31 October 2012 /

Published: 5 November 2012

\begin{abstract}
Three new $\gamma$-butenolide derivatives 1-3, named spiculisporic acids B-D, were isolated from the culture of Aspergillus sp. HDf2, a marine-derived fungus that resides in the sea urchin, Anthocidaris crassispina. The structures of 1-3 were elucidated on the basis of spectroscopic methods, including MS and 2D NMR techniques. Their in vitro cytotoxic activities against two cell lines (SGC-7901, human gastric adenocarcinoma and SPC-A-1, human lung adenocarcinoma) and inhibitory activities against Staphylococcus aureus ATCC 51650 were investigated.
\end{abstract}

Keywords: $\gamma$-butenolide derivatives; spiculisporic acids B-D; Aspergillus sp.; marine fungus

\section{Introduction}

Microorganisms of marine origin have proven to be a rich source of novel and/or biologically active natural products with promising pharmacological properties [1-4]. In related studies, the Tsukamoto laboratory reported a new antimicrobial anthraquinone (monodictyquinone A) from a sea urchin-derived fungus Monodictys sp. [5]. In our search for new natural products from marine-derived microorganisms, the fungus Aspergillus sp. HDf2 was isolated from the sea urchin Anthocidaris crassispina, collected from the seashore of Qionghai, Hainan, China. The genus Aspergillus (Trichocomaceae) is one of the most prolific fungi that produce a variety of secondary metabolites 
with novel structures and interesting bioactivities [6]. Subsequent chemical study on the fermentation broth of the fungus Aspergillus sp. HDf2 led to the isolation of three new $\gamma$-butenolide derivatives, the structures of which were similar to that of spiculisporic acid [7,8], and these compounds were thus named as spiculisporic acids B-D (compounds 1-3, Figure 1). Their structures were elucidated by comprehensive spectroscopic analyses. Herein we report the isolation, structural determination, bioactivities of these new natural products.

Figure 1. Structures of compounds 1-3.
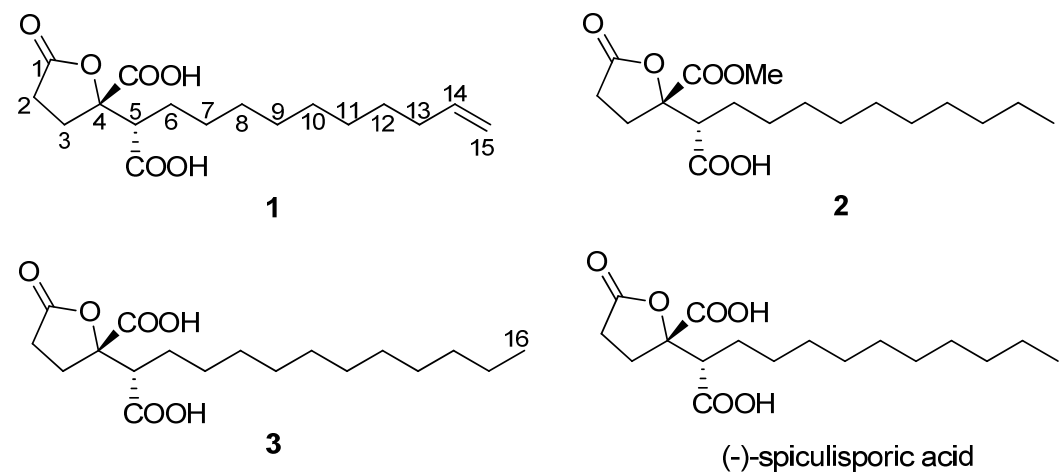

\section{Results and Discussion}

Spiculisporic acid B (1) was isolated as a white solid, with the molecular formula $\mathrm{C}_{17} \mathrm{H}_{26} \mathrm{O}_{6}$ (five degrees of unsaturation) as derived from ESI high-resolution mass spectrometry $\left([\mathrm{M}-\mathrm{H}]^{-}\right.$at $\mathrm{m} / \mathrm{z}$ 325.1664, calculated 325.1657) and ${ }^{1} \mathrm{H}$ - and ${ }^{13} \mathrm{C}$-NMR spectral data (Tables 1 and 2). The ${ }^{13} \mathrm{C}-\mathrm{NMR}$ showed three carbonyl carbons at $\delta_{\mathrm{C}} 178.5,175.5$, and 174.2, one olefinic methine carbon at $\delta_{\mathrm{C}} 140.2$, one olefinic methylene carbon at $\delta_{\mathrm{C}} 114.8$, one oxygen bearing quaternary carbon at $\delta_{\mathrm{C}} 88.2$, one methine carbon at $\delta_{\mathrm{C}} 52.5$, and ten aliphatic carbons in the upfield $\left(\delta_{\mathrm{C}} 35.0\right.$ to 28.9$)$ region. The ${ }^{1} \mathrm{H}-\mathrm{NMR}$ spectrum displayed signals of one terminal vinyl group at $\delta_{\mathrm{H}} 5.81$ (ddt, $J=16.1,10.2,6.8 \mathrm{~Hz}, \mathrm{H}-14$ ), 4.98 (br d, $J=16.1 \mathrm{~Hz}, \mathrm{H}-15 \mathrm{a}$ ), and 4.91 (br d, $J=10.2 \mathrm{~Hz}, \mathrm{H}-15 \mathrm{~b}$ ), and 21 aliphatic protons. Together, these data indicate that compound 1 has one double bond and three carbonyls, which account for 4 out of the 5 degrees of unsaturation required by the molecular formula, so spiculisporic acid B must contain a ring. The structural information for $\mathbf{1}$ was determined from a series of 2D NMR analyses, including HSQC, ${ }^{1} \mathrm{H}-{ }^{1} \mathrm{H}$ COSY, and $\mathrm{HMBC}$ spectra (Figure 2). The ${ }^{1} \mathrm{H}-{ }^{1} \mathrm{H}$ COSY experiment revealed a correlation between $\mathrm{H}-2\left(\delta_{\mathrm{H}} 2.60\right)$ and $\mathrm{H}-3\left(\delta_{\mathrm{H}} 2.49\right)$, and a seperate spin system, $\mathrm{H}_{2} \mathrm{C}=\mathrm{CH}-\mathrm{CH}_{2}-\left(\mathrm{CH}_{2}\right)_{6}-\mathrm{CH}_{2}-\mathrm{CH}-$. The methine proton $\mathrm{H}-14$ was coupled with the methylene protons $\mathrm{H}-13\left(\delta_{\mathrm{H}} 2.04\right)$ and $\mathrm{H}-15$, and the methylene proton $\mathrm{H}-13$ was coupled with the methylene proton at $\mathrm{H}-12\left(\delta_{\mathrm{H}} 1.37\right)$. The correlations between the methylene proton $\mathrm{H}-6 \mathrm{a}\left(\delta_{\mathrm{H}} 1.85\right)$ and $\mathrm{H}-5$ $\left[\delta_{\mathrm{H}} 3.01(\mathrm{br} \mathrm{d}, J=9.2 \mathrm{~Hz})\right]$ and $\mathrm{H}-7\left(\delta_{\mathrm{H}} 1.25-1.37\right)$ were observed in the ${ }^{1} \mathrm{H}-{ }^{1} \mathrm{H}$ COSY spectrum. HMBC correlations from $\mathrm{H}-5$ to $\mathrm{C}-4\left(\delta_{\mathrm{C}} 88.2\right)$ and two carbonyl carbons $\left(\delta_{\mathrm{C}} 175.5\right.$ and 174.2), from $\mathrm{H}-3$ to $\mathrm{C}-1\left(\delta_{\mathrm{C}} 178.5\right), \mathrm{C}-4, \mathrm{C}-5\left(\delta_{\mathrm{C}} 52.5\right)$, and one of the carbonyl carbons $\left(\delta_{\mathrm{C}} 174.2\right)$, and from $\mathrm{H}-2$ to $\mathrm{C}-1$ and $\mathrm{C}-4$, were observed. These observations allowed the structure of $\mathbf{1}$ to be determined as shown in Figure 1. 
Table 1. ${ }^{1} \mathrm{H}-\mathrm{NMR}$ spectral data $\left(500 \mathrm{MHz}, \mathrm{CD}_{3} \mathrm{OD}\right)$ of compounds $\mathbf{1}-\mathbf{3}$.

\begin{tabular}{cccc}
\hline Position & $\mathbf{1}$ & $\mathbf{2}$ & $\mathbf{3}$ \\
\hline 2 & $2.60(\mathrm{~m})$ & $2.59(\mathrm{~m})$ & $2.59(\mathrm{~m})$ \\
3 & $2.49(\mathrm{~m})$ & $2.48(\mathrm{~m})$ & $2.46(\mathrm{~m})$ \\
$4-$ COOMe & & $3.80(\mathrm{~s})$ & \\
5 & $3.01(\mathrm{brd}, J=9.2)$ & $2.97(\mathrm{dd}, J=10.8,2.5)$ & $3.03(\mathrm{dd}, J=11.0,3.0)$ \\
6 & $1.85(\mathrm{~m}) ; 1.50(\mathrm{~m})$ & $1.82(\mathrm{~m}) ; 1.51(\mathrm{~m})$ & $1.85(\mathrm{~m}) ; 1.53(\mathrm{~m})$ \\
7 & $1.25-1.37(\mathrm{~m})^{a}$ & $1.43(\mathrm{~m}) ; 1.32(\mathrm{~m})$ & $1.42(\mathrm{~m}) ; 1.32(\mathrm{~m})$ \\
8 & $1.25-1.37(\mathrm{~m})^{a}$ & $1.25-1.37(\mathrm{~m})^{b}$ & $1.25-1.38(\mathrm{~m})^{c}$ \\
9 & $1.25-1.37(\mathrm{~m})^{a}$ & $1.25-1.37(\mathrm{~m})^{b}$ & $1.25-1.38(\mathrm{~m})^{c}$ \\
10 & $1.25-1.37(\mathrm{~m})^{a}$ & $1.25-1.37(\mathrm{~m})^{b}$ & $1.25-1.38(\mathrm{~m})^{c}$ \\
11 & $1.25-1.37(\mathrm{~m})^{a}$ & $1.25-1.37(\mathrm{~m})^{b}$ & $1.25-1.38(\mathrm{~m})^{c}$ \\
12 & $1.37(\mathrm{~m})$ & $1.25-1.37(\mathrm{~m})^{b}$ & $1.25-1.38(\mathrm{~m})^{c}$ \\
13 & $2.04(\mathrm{~m})$ & $1.25-1.37(\mathrm{~m})^{b}$ & $1.25-1.38(\mathrm{~m})^{c}$ \\
14 & $5.81(\mathrm{ddt}, J=16.1,10.2,6.8)$ & $1.25-1.37(\mathrm{~m})^{b}$ & $1.25-1.38(\mathrm{~m})^{c}$ \\
15 & $4.98(\mathrm{br} \mathrm{d}, J=16.1)$ & $0.90(\mathrm{t}, J=6.8)$ & $1.25-1.38(\mathrm{~m})^{c}$ \\
16 & $4.91(\mathrm{brd} \mathrm{d}, J=10.2)$ & & $0.90(\mathrm{t}, J=7.0)$ \\
\hline
\end{tabular}

${ }^{a-c}$ Overlapping signals.

Table 2. ${ }^{13} \mathrm{C}-\mathrm{NMR}$ spectral data $\left(125 \mathrm{MHz}, \mathrm{CD}_{3} \mathrm{OD}\right)$ of compounds 1-3.

\begin{tabular}{cccc}
\hline Position & $\mathbf{1}$ & $\mathbf{2}$ & $\mathbf{3}$ \\
\hline 1 & $178.5(\mathrm{~s})$ & $178.0(\mathrm{~s})$ & $178.7(\mathrm{~s})$ \\
2 & $28.9(\mathrm{t})^{a}$ & $28.7(\mathrm{t})$ & $29.0(\mathrm{t})^{e}$ \\
3 & $30.3(\mathrm{t})$ & $30.5(\mathrm{t})$ & $30.6(\mathrm{t})^{d}$ \\
4 & $88.2(\mathrm{~s})$ & $88.2(\mathrm{~s})$ & $88.7(\mathrm{~s})$ \\
$4-\mathrm{COOH}$ & $174.2(\mathrm{~s})$ & & $174.9(\mathrm{~s})$ \\
$4-\mathrm{CO}$ & & $172.8(\mathrm{~s})$ & \\
OMe & & $53.6(\mathrm{q})$ & \\
5 & $52.5(\mathrm{~d})$ & $52.9(\mathrm{~d})$ & $52.7(\mathrm{~d})$ \\
$5-\mathrm{COOH}$ & $175.5(\mathrm{~s})$ & $175.2(\mathrm{~s})$ & $175.8(\mathrm{~s})$ \\
6 & $29.2(\mathrm{t})$ & $28.9(\mathrm{t})^{b}$ & $29.1(\mathrm{t})$ \\
7 & $28.9(\mathrm{t})^{a}$ & $28.9(\mathrm{t})^{b}$ & $29.0(\mathrm{t})^{e}$ \\
8 & $30.7(\mathrm{t})^{f}$ & $30.5(\mathrm{t})^{c, g}$ & $30.6(\mathrm{t})^{d}$ \\
9 & $30.4(\mathrm{t})^{f}$ & $30.4(\mathrm{t})^{g}$ & $30.6(\mathrm{t})^{d, h}$ \\
10 & $30.5(\mathrm{t})^{f}$ & $30.5(\mathrm{t})^{c, g}$ & $30.8(\mathrm{t})^{h}$ \\
11 & $30.5(\mathrm{t})^{f}$ & $30.8(\mathrm{t})^{g}$ & $30.9(\mathrm{t})^{h}$ \\
12 & $30.2(\mathrm{t})$ & $30.7(\mathrm{t})^{g}$ & $30.7(\mathrm{t})^{h}$ \\
13 & $35.0(\mathrm{t})$ & $33.1(\mathrm{t})$ & $30.5(\mathrm{t})$ \\
14 & $140.2(\mathrm{~d})$ & $23.8(\mathrm{t})$ & $33.2(\mathrm{t})$ \\
15 & $114.8(\mathrm{t})$ & $14.5(\mathrm{q})$ & $23.8(\mathrm{t})$ \\
16 & & & $14.5(\mathrm{q})$ \\
\hline$a^{-e}$ Overlapping signals. $^{f-h}$ Interchangeable signals. $^{h}$
\end{tabular}


Figure 2. ${ }^{1} \mathrm{H}-{ }^{1} \mathrm{H}$ COSY and selected HMBC correlations of compounds 1-3.

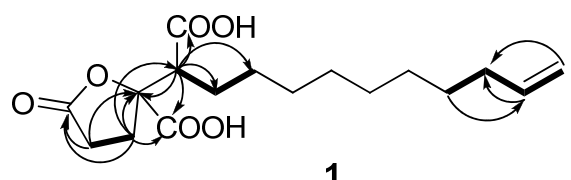

1

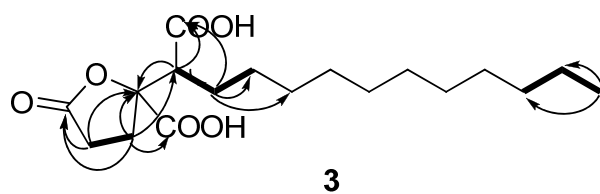

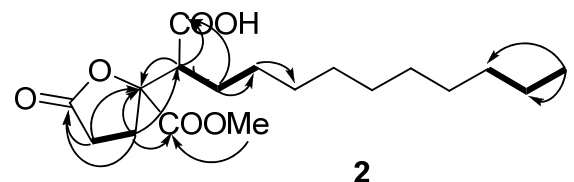

2

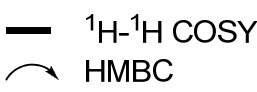

To confirm the absolute configuration of 1 , through comparison of its chemical shifts for C-4 $\left(\delta_{\mathrm{C}}\right.$ 88.2) and C-5 $\left(\delta_{\mathrm{C}} 52.5\right)$ with those of the known compounds $(-)$-spiculisporic acid $\left(\delta_{\mathrm{C}} 88.1,52.5\right)$ and $(-)$-epispiculisporic acid $\left(\delta_{\mathrm{C}} 88.0,51.9\right)$ [7,8], we tentatively propose the absolute configuration at C-4 and $\mathrm{C}-5$ in 1 to be $4 S$ and $5 S$ as (-)-spiculisporic acid. Thus, the structure was identified as $(4 S, 5 S)-4-$ (5-carboxyl-undecyl-14-enyl)-1-oxo-tetrahydrofuran-4-carboxyl acid, named spiculisporic acid B.

Spiculisporic acid C (2) was obtained as a waxy solid that analyzed for the molecular formula $\mathrm{C}_{18} \mathrm{H}_{30} \mathrm{O}_{6}$ by HR-ESI-MS data $\left([\mathrm{M}+\mathrm{Na}]^{+} \mathrm{m} / z\right.$ 365.1927), and by comprehensive analysis of NMR data. This formula differed by the addition of $\mathrm{CH}_{2}$ to the molecular formula of spiculisporic acid [7,8], suggesting an additional methylene or methyl group had been added to the structure. The ${ }^{1} \mathrm{H}$ and ${ }^{13} \mathrm{C}$-NMR data for 2 were almost identical to those of spiculisporic acid, except for the presence of a new oxygenated methyl group $\left(\delta_{\mathrm{C}} 53.6, \delta_{\mathrm{H}} 3.80\right)$. The HMBC spectrum showed a strong correlation between the oxygenated methyl protons and carbonyl carbon at $\delta_{\mathrm{C}} 172.8$, which was correlated with H-3 $\left(\delta_{\mathrm{H}} 2.48\right)$, thus indicating the position of the methoxyl group. Based on the HSQC, ${ }^{1} \mathrm{H}-{ }^{1} \mathrm{H}$ COSY, and HMBC analyses of 2 (Figure 2), and the good comparison of NMR data of C-4 $\left(\delta_{\mathrm{C}} 88.2\right)$ and C-5 $\left(\delta_{\mathrm{C}} 52.9\right)$ in 2 to those from (-)-spiculisporic acid, we proposed the structure of 2 to be $(4 S, 5 S)-4$-(5-carboxylundecyl)-1-oxo-tetrahydrofuran-4-carboxyl acid methyl ester, named spiculisporic acid C. It was possible that the methoxyl group in $\mathbf{2}$ was a result of a reaction with methanol in the procedure of isolation.

Spiculisporic acid D (3), isolated as a pale white solid, gave a $[\mathrm{M}+\mathrm{Na}]^{+}$ion peak at $\mathrm{m} / \mathrm{z} 365.1940$ in its positive-mode HR-ESI-MS, indicating its molecular formula to be $\mathrm{C}_{18} \mathrm{H}_{30} \mathrm{O}_{6}$, which was the same as that of 2 . Through detailed analyses of the ${ }^{1} \mathrm{H}$ - and ${ }^{13} \mathrm{C}-\mathrm{NMR}$ spectra of $\mathbf{3}$, the major difference between 3 and spiculisporic acid was the presence of a new methylene group in the aliphatic chain. Unambiguous assignments of ${ }^{1} \mathrm{H}$ - and ${ }^{13} \mathrm{C}-\mathrm{NMR}$ data were obtained by interpretation of HSQC, ${ }^{1} \mathrm{H}-{ }^{1} \mathrm{H}$ COSY, and HMBC data (Figure 2), confirming the structure for $\mathbf{3}$ as shown. The absolute configuration of $\mathbf{3}$, determined by comparison of NMR data of C-4 $\left(\delta_{\mathrm{C}} 88.7\right)$ and C-5 $\left(\delta_{\mathrm{C}} 52.7\right)$ in 3 with those of $(-)$-spiculisporic acid, was elucidated as (4S,5S)-4-(5-carboxyl-dodecyl)-1-oxotetrahydrofuran-4-carboxyl acid, named spiculisporic acid D.

Compounds 1-3 were subjected to cytotoxic activity tests against two cell lines, SGC-7901 and SPC-A-1 by MTT methods [9]. However, none of these compounds were active with $\mathrm{IC}_{50}>50 \mu \mathrm{g} / \mathrm{mL}$. Compounds 1-3 showed antibacterial activities against Staphylococcus aureus ATCC 51650 with inhibition zone of $9.6,11.6$, and $11.5 \mathrm{~mm}$ at $20 \mathrm{mg} / \mathrm{mL}$, while the diameter of inhibition zone of the positive control was $23.6 \mathrm{~mm}$. Spiculisporic acid, a fermentation adduct from the culture broth of Penicillium spiculisporum has found potential use as new controlled release carriers of active 
chemicals [7], and commercial application as a biosurfactant for metal decontamination processes to remove hard, large metal cations from water [10]. These interesting properties of spiculisporic acids $\mathrm{B}-\mathrm{D}$ are currently under investigation.

\section{Experimental}

\subsection{General Experimental Procedures}

Optical rotations were taken on a Rudolph Autopol III. UV spectra were measured on a Hitachi U-3000 spectrophotometer, and IR spectra (KBr) were obtained on a Nicolet 380 FT-IR spectrometer. NMR spectra were recorded on a Bruker AVIII-500 spectrometer at $500 \mathrm{MHz}$ for ${ }^{1} \mathrm{H}-\mathrm{NMR}$ and at $125 \mathrm{MHz}$ for ${ }^{13} \mathrm{C}-\mathrm{NMR}$. Chemical shifts are given in $\delta(\mathrm{ppm})$ and referenced to the solvent signal (methanol- $d_{4}, \delta_{\mathrm{H}} 3.31, \delta_{\mathrm{C}} 49.1$ ) as the internal standard, and coupling constants $(J)$ are reported in Hz. HR-ESI-MS spectra were recorded on a Agilent 6210 TOF LC/MS mass spectrometer. Silica gel (200-300 mesh) for column chromatography (CC) and silica $\mathrm{GF}_{254}$ (10-20 mm) for TLC were obtained from Qingdao Marine Chemical Factory (Qingdao, China). YMC ODS gel (50 $\mu \mathrm{m})$ was purchased from Shanghai HANKING Instrument \& Equipment Co., Ltd. (Shanghai, China) Sephadex LH-20 for chromatography was purchased from Merck (Darmstadt, Germany). Semipreparative HPLC was performed on a Hitachi L-7110 pump, and UV detector L-7400 equipped with a Waters ODS column $(5 \mu \mathrm{m}, 250 \times 4.6 \mathrm{~mm})$.

\subsection{Fungal Material and Cultivation}

The fungus Aspergillus sp. HDf2 was isolated and identified by one of the authors (R.W.) from the gut of a healthy sea urchin Anthocidaris crassispina collected from the seashore of Qionghai, Hainan, China, in October 2009. A voucher specimen with the code HNF-HD02 is deposited in the Hainan Provincial Fisheries Research Institute. The fungus was cultivated on MEA solid medium composed of $20 \mathrm{~g} / \mathrm{L}$ malt extract, $20 \mathrm{~g} / \mathrm{L}$ sucrose, $1 \mathrm{~g} / \mathrm{L}$ peptone, $20 \mathrm{~g} / \mathrm{L}$ agar and deionized water for 5 days at $28{ }^{\circ} \mathrm{C}$. Agar plugs were used to inoculate in 1000-mL Erlenmeyer flasks, each containing $300 \mathrm{~mL}$ of ME liquid media. Fermentation was carried out on a rotary shaker $(140 \mathrm{rpm})$ at $26{ }^{\circ} \mathrm{C}$ for 12 days in $40 \times 1,000 \mathrm{~mL}$ Erlenmeyer flasks.

\subsection{Extraction and Isolation}

The filtrate $(12 \mathrm{~L})$ of the fermented culture broth was extracted three times with EtOAc $(12 \mathrm{~L} \times 4)$ at room temperature, and the organic solvent was evaporated to dryness under reduced pressure to afford a yellow crude extract $(4.1 \mathrm{~g})$, which was subjected to silica gel (41 g, 200-300 mesh) CC (4 $\times 75 \mathrm{~cm})$ eluted with a gradient of $\mathrm{CHCl}_{3}-\mathrm{MeOH}(\mathrm{v} / \mathrm{v}$ 100:0, 100:1, 100:2, 100:4, 100:8, 100:16 and 0:100, each $600 \mathrm{~mL}$ ) to give seven fractions. The $\mathrm{CHCl}_{3}-\mathrm{MeOH}(100: 4)$ fraction $(710.3 \mathrm{mg})$ was further purified by Sephadex LH-20 CC $(1.5 \times 30 \mathrm{~cm})$ eluting with $\mathrm{MeOH}(500 \mathrm{~mL})$ and then by ODS CC $(2.5 \times 40 \mathrm{~cm})$ with a gradient of $\mathrm{MeOH}-\mathrm{H}_{2} \mathrm{O}(\mathrm{v} / \mathrm{v}$ 50:50, 65:35, 80:20, 100:0, each $400 \mathrm{~mL})$ to afford a fraction (110.5 mg) (MeOH- $\left.\mathrm{H}_{2} \mathrm{O}, 80: 20\right)$ containing 1-3, which were purified by semipreparative reversed-phase HPLC [2 mL/min; MeOH-0.1\% TFA in $\mathrm{H}_{2} \mathrm{O}$ (78:22)] (1, $10.3 \mathrm{mg}, t_{\mathrm{R}}=16.0 \mathrm{~min} ; 2,16.2 \mathrm{mg}$, $\left.t_{\mathrm{R}}=27.8 \mathrm{~min} ; \mathbf{3}, 22.6 \mathrm{mg}, t_{\mathrm{R}}=29.6 \mathrm{~min}\right)$. All these compounds were stored at $4{ }^{\circ} \mathrm{C}$. 
Spiculisporic acid B (1): (4S,5S)-4-(5-Carboxylundecyl-14-enyl)-1-oxo-tetrahydrofuran-4-carboxylic acid. White solid; $[\alpha]^{30}{ }_{\mathrm{D}}=-4.8(\mathrm{c}=0.028, \mathrm{EtOH}) ; \mathrm{UV}(\mathrm{MeOH}) \lambda_{\max }(\log \varepsilon): 199$ (3.07), 215 (3.89) $\mathrm{nm}$; IR (KBr) $v_{\max }: 2912,2853,1711,1688,1415,1272,1175,932 \mathrm{~cm}^{-1} ;{ }^{1} \mathrm{H}$ and ${ }^{13} \mathrm{C}-\mathrm{NMR}$ spectral data are listed in Tables 1 and 2; HR-ESI-MS: $m / z 325.1664[\mathrm{M}-\mathrm{H}]^{-}$(calculated for $\mathrm{C}_{17} \mathrm{H}_{25} \mathrm{O}_{6}$, 325.1657).

Spiculisporic acid C (2): (4S,5S)-4-(5-Carboxylundecyl)-1-oxo-tetrahydrofuran-4-carboxylic acid methyl ester. Waxy solid; $[\alpha]^{30}{ }_{\mathrm{D}}=-24.7(\mathrm{c}=0.078, \mathrm{EtOH}) ; \mathrm{UV}(\mathrm{MeOH}) \lambda_{\max }(\log \varepsilon): 214(3.18) \mathrm{nm}$; IR (KBr) $v_{\text {max }}: 2921,2855,1716,1663,1412,1274,1183,952 \mathrm{~cm}^{-1} ;{ }^{1} \mathrm{H}$ and ${ }^{13} \mathrm{C}-\mathrm{NMR}$ spectral data are listed in Tables 1 and 2; HR-ESI-MS: $m / z 365.1927[\mathrm{M}+\mathrm{Na}]^{+}$(calculated for $\mathrm{C}_{18} \mathrm{H}_{30} \mathrm{O}_{6} \mathrm{Na}$, $365.1935)$.

Spiculisporic acid D (3): (4S,5S)-4-(5-Carboxyldodecyl)-1-oxo-tetrahydrofuran-4-carboxylic acid. Pale white solid; $[\alpha]^{30}{ }_{\mathrm{D}}=-11.8(\mathrm{c}=0.028, \mathrm{EtOH}) ; \mathrm{UV}(\mathrm{MeOH}) \lambda_{\max }(\log \varepsilon): 212(3.22) \mathrm{nm}$; IR $(\mathrm{KBr})$ $v_{\max }: 2918,2860,1721,1657,1423,1268,1175,944 \mathrm{~cm}^{-1} ;{ }^{1} \mathrm{H}$ and ${ }^{13} \mathrm{C}-\mathrm{NMR}$ spectral data are listed in Tables 1 and 2; HR-ESI-MS: $\mathrm{m} / z$ 365.1940 [M+Na] ${ }^{+}$(calculated for $\mathrm{C}_{18} \mathrm{H}_{30} \mathrm{O}_{6} \mathrm{Na}, 365.1935$ ).

\subsection{In Vitro Cytotoxicity Test}

The cytotoxic activities for compounds 1-3 were tested in vitro against two cell lines, SGC-7901 (human gastric adenocarcinoma) and SPC-A-1 (human lung adenocarcinoma), which were purchased from the Jiangsu Provincial Center for Disease Prevention and Control. The purity of the tested compounds and doxorubicin $\mathrm{HCl}$ was determined to be over $95 \%$ by using the HPLC-DAD method. The cytotoxic in vitro effects on these tested cell were assessed by the $\mathrm{IC}_{50}$ values, and determined by the MTT [3-(4,5-dimethylthiazol-2-yl)-2,5-diphenyltetrazolium bromide] colometric method [8]. Each set of test was conducted three times to confirm reproducibility of the results. The compounds were dissolved in DMSO (dimethyl sulfoxide). Doxorubicin $\cdot \mathrm{HCl}$ was used as a positive control, and the medium without test compound as a negative control in the bioassay.

\subsection{Antibacterial Test}

Compounds 1-3 were tested for in vitro antimicrobial activity against Staphylococcus aureus ATCC51650 by the filter paper disc agar diffusion method. The NA medium was mixed with $2 \mathrm{~mL}$ of suspension containing $1 \times 10^{5} \sim 1 \times 10^{7} \mathrm{cfu} / \mathrm{mL}$ of Staphylococcus aureus, and then poured into petri-plates. $2 \mu \mathrm{L} 20 \mathrm{mg} / \mathrm{mL}$ of the isolated compounds dissolved in DMSO were impregnated on sterile filter paper discs (6 mm diameter) and then were applied on the surface of the solidified agar plates. Every sample was tested in triplicate. Streptomycin sulfate $(2 \mu \mathrm{L}, 20 \mathrm{mg} / \mathrm{mL})$ was used as positive control. The test plates were incubated at $37{ }^{\circ} \mathrm{C}$ for $24 \mathrm{~h}$. Then the diameters of the inhibition zones including the $6 \mathrm{~mm}$ disc diameter were measured.

\section{Conclusions}

In our screening for new secondary metabolites from marine-derived fungi associated with marine animals from the coast of Hainan Island, three new secondary metabolites 1-3, named spiculisporic 
acids B-D were isolated from a sea urchin (Anthocidaris crassispina)-associated fungus Aspergillus sp. HDf2 for the first time and characterized. Their structures were elucidated by NMR spectroscopic methods, and the absolute configurations were determined by comparing the chemical shifts of their chiral carbons with those of related known analogues. The compounds displayed no cytotoxic activity against human gastric adenocarcinoma cell line SGC-7901 and human lung adenocarcinoma cell line SPC-A-1 with $\mathrm{IC}_{50}>50 \mu \mathrm{g} / \mathrm{mL}$. Compounds 1-3 showed weak antibacterial activities against Staphylococcus aureus ATCC 51650 at $20 \mathrm{mg} / \mathrm{mL}$. Further research into their new activities is in progress.

\section{Supplementary Materials}

Supplementary materials can be accessed at: http://www.mdpi.com/1420-3049/17/11/13175/s1.

\section{Acknowledgments}

This work was supported by funds for the Science and Technology Program of Hainan Province to Promote the Research and Development of Marine Resources, and the Fundamental Research Foundation for Youth, Hainan Provincial Fisheries Research Institute (No.20091006).

\section{References}

1. Li, D.; Xu, Y.; Shao, C.L.; Yang, R.Y.; Zheng, C.J.; Chen, Y.Y.; Fu, X.M.; Qian, P.Y.; She, Z.G.; de Voogd, N.J.; et al. Antibacterial bisabolane-type sesquiterpenoids from the sponge-derived fungus Aspergillus sp. Mar. Drugs 2012, 10, 234-241.

2. Gao, S.S.; Li, X.M.; Du, F.Y.; Li, C.S.; Proksch, P.; Wang, B.G. Secondary metabolites from a marine-derived endophytic fungus Penicillium chrysogenum QEN-24S. Mar. Drugs 2011, 9, 59-70.

3. Blunt, J.W.; Copp, B.R.; Munro, M.H.G.; Northcote, P.T.; Prinsep, M.R. Marine natural products. Nat. Prod. Rep. 2011, 28, 196-268.

4. Kwon, H.C.; Kauffman, C.A.; Jensen, P.R.; Fenical, W. Marinisporolides, Polyene-polyol macrolides from a marine actinomycete of the new genus "Marinispora". J. Org. Chem. 2009, 74, 675-684.

5. El-Beih, A.A.; Kawabata, T.; Koimaru, K.; Ohta, T.; Tsukamoto, S. Monodictyquinone A: A new antimicrobial anthraquinone from a sea urchin-derived fungus Monodictys sp. Chem. Pharm. Bull. 2007, 55, 1097-1098.

6. Keller, N.P.; Turner, G.; Bennett, J.W. Fungal secondary metabolism-From biochemistry to genomics. Nat. Rev. Microbiol. 2005, 3, 937-947.

7. Brown, S.P.; Goodwin, N.C.; MacMillan, D.W.C. The first enantioselective organocatalytic Mukaiyama-Michael reaction: A direct method for the synthesis of enantioenriched $\gamma$-Butenolide Architecture. J. Am. Chem. Soc. 2003, 125, 1192-1194.

8. Asano, M.; Kameda, S. Spiculisporic acid, a metabolic product of Penicillium. Rept. Jpn. Assoc. Adv. Sci. 1942, 17, 60-64.

9. Mosmann, T. Rapid colorimetric assay for cellular growth and survival: Application to proliferation and cytotoxicity assays. J. Immun. Methods 1983, 65, 55-63. 
10. Pekdemir, T.; Tokunaga, S.; Ishigami, Y.; Hong, H.-J. Removal of cadmium or lead from polluted water by biological amphiphiles. J. Surfactants Deterg. 2000, 3, 43-46.

Samples Availability: Samples are available from the authors.

(C) 2012 by the authors; licensee MDPI, Basel, Switzerland. This article is an open access article distributed under the terms and conditions of the Creative Commons Attribution license (http://creativecommons.org/licenses/by/3.0/). 